Table 1. Response rates in patients over 12 months, with or without baseline GC (FAS)

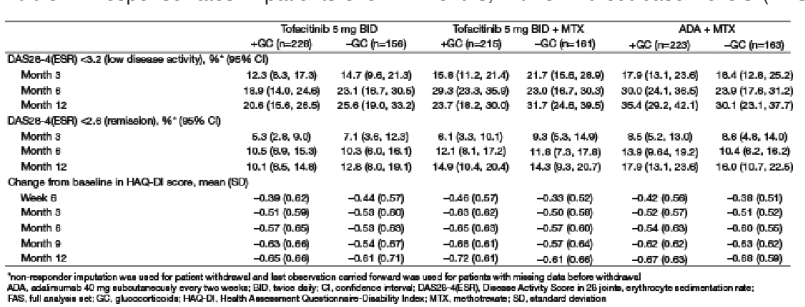

Table 2. Summary of AEs, discontinuations due to AEs, SAEs and SIEs over 12 months

\begin{tabular}{|c|c|c|c|c|c|c|}
\hline \multirow[b]{3}{*}{ AEs, n (M) } & \multicolumn{2}{|c|}{ Toffecitinib $5 \mathrm{mg}$ BlD } & \multicolumn{2}{|c|}{ Tefecifficib $5 \mathrm{mg}$ BiD + MTX } & \multicolumn{2}{|c|}{$A D A+M T X$} \\
\hline & $+\operatorname{SCC}(n=228)$ & $-\operatorname{se}(n=158)$ & $+6 C(n=215)$ & $-6 C n=181)$ & $+6 C(n=229)$ & $-\operatorname{GCC}(n=1893)$ \\
\hline & $\pi(30.8)$ & $5(30.5)$ & $\begin{array}{l}80(41.9) \\
1(0.5)\end{array}$ & $74(40.0)$ & $86(90.6)$ & $80(4-1.7)$ \\
\hline 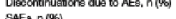 & $6(2.6)$ & 110 & $1(0.5)$ & 42.5 & $4(1,8)$ & $6(a .7)$ \\
\hline 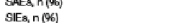 & $\begin{array}{l}3(.3) \\
2(0.8)\end{array}$ & 11(7.1) & $\begin{array}{l}17(7.8) \\
1(0.5)\end{array}$ & $\begin{array}{l}81.64 \\
240.24\end{array}$ & $5(2.2)$ & $\begin{array}{l}8.4 .99 \\
20.91\end{array}$ \\
\hline 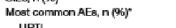 & & & & & & \\
\hline Nasophanngitis & (114.89) & $\begin{array}{l}127.74 \\
11(7.1)\end{array}$ & $\begin{array}{lll} & \end{array}$ & 等 & (7.0.9 & $\begin{array}{l}12(7) 4) \\
8(5.55\end{array}$ \\
\hline 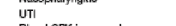 & $3(1.3)$ & (3. $(5.1)$ & $10(4.7)$ & sis.1) & $8(3.8)$ & 80.9 .9 \\
\hline Blood CFK increased & $5(2.2)$ & $\begin{array}{l}5(3.1) \\
5(3.2)\end{array}$ & 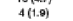 & 815.09 & $\begin{array}{l}0.01 \\
+(0.4)\end{array}$ & $4(2.5)$ \\
\hline ALT increasead & $4(1.6)$ & $4(2.6)$ & $10\left(4 . T_{i}\right.$ & $13(8.1)$ & $18(0.1)$ & 8 (4.,.g] \\
\hline ABT inoraceed & $2(0.0)$ & $2(13)$ & $8(2,8)$ & $10(8.2)$ & $11(4.9)$ & \\
\hline
\end{tabular}

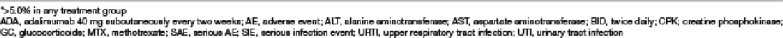

Conclusions: In pts with RA, concomitant stable GC use did not appear to impact the efficacy of tofacitinib $5 \mathrm{mg}$ BID \pm MTX or ADA+MTX. The finding that GC use was not associated with higher AE rates was unexpected and of interest.

Acknowledgements: Study sponsored by Pfizer Inc. Medical writing support was provided by $\mathrm{C}$ Viegelmann of $\mathrm{CMC}$ and funded by Pfizer Inc.

Disclosure of Interest: R. Fleischmann Grant/research support from: AbbVie, Amgen, AstraZeneca, Bristol-Myers Squibb, Celltrion, Eli Lilly, Genentech, GSK, Janssen, Novartis, Pfizer Inc, Sanofi-Aventis, UCB, Consultant for: AbbVie, Amgen, AstraZeneca, Bristol-Myers Squibb, Celltrion, Eli Lilly, Genentech, GSK, Janssen, Novartis, Pfizer Inc, Sanofi-Aventis, UCB, J. Wollenhaupt Consultant for: Pfizer Inc, Speakers bureau: Pfizer Inc, S. Cohen Grant/research support from: AbbVie, Amgen, Astellas, Bristol-Meyers Squibb, Eli Lilly, Genentech, Gilead, Janssen, Novartis, Pfizer Inc, Roche, Sandoz, Consultant for: AbbVie, Amgen, Astellas, Bristol-Meyers Squibb, Eli Lilly, Genentech, Gilead, Janssen, Novartis, Pfizer Inc, Roche, Sandoz, J. Smolen Grant/research support from: AbbVie, Eli Lilly, Janssen, MSD, Pfizer Inc, Roche, Consultant for: AbbVie, Amgen, AstraZeneca, Astro, Celgene, Celltrion, Eli Lilly, GSK, ILTOO, Janssen, Medlmmune, MSD, Novartis-Sandoz, Pfizer Inc, Roche, Samsung, Sanofi, UCB, Speakers bureau: AbbVie, Amgen, AstraZeneca, Astro, Celgene, Celltrion, Eli Lilly, GSK, ILTOO, Janssen, Medlmmune, MSD, Novartis-Sandoz, Pfizer Inc, Roche, Samsung, Sanofi, UCB, P. Dahl Shareholder of: Pfizer Inc, Employee of: Pfizer Inc, N. likuni Shareholder of: Pfizer Inc, Employee of: Pfizer Inc, H. Shi Shareholder of: Pfizer Inc, Employee of: Pfizer Inc, S. Tatulych Shareholder of: Pfizer Inc, Employee of: Pfizer Inc, L. Takiya Shareholder of: Pfizer Inc, Employee of: Pfizer Inc

DOI: 10.1136/annrheumdis-2018-eular.1533

\section{SAT0248 A MULTICENTER STUDY ASSESSING THE EFFICACY AND SAFETY OF REPOSITORY CORTICOTROPIN INJECTION IN PATIENTS WITH RHEUMATOID ARTHRITIS: PRELIMINARY INTERIM DATA FROM THE OPEN-LABEL TREATMENT PERIOD}

R. Fleischmann ${ }^{1}$, D. E. Furst ${ }^{2}$, R. Brasington ${ }^{3}$, E. Connolly-Strong ${ }^{4}$, J. Liu ${ }^{4}$, M. E. Barton ${ }^{4} .{ }^{1}$ Southwestern Medical Center, University of Texas, Dallas, ${ }^{2}$ David Geffen School of Medicine, University of California at Los Angeles, Los Angeles, ${ }^{3}$ School of Medicine, Washington University, St. Louis, ${ }^{4}$ Mallinckrodt, ARD Inc, Bedminster, United States

Background: Rheumatoid arthritis (RA) is an autoimmune disorder associated with chronic inflammation that is commonly treated with disease-modifying antirheumatic drugs (DMARD) and corticosteroids. Repository corticotropin injection $(\mathrm{RCl})$ is approved in the United States as adjunctive therapy for short-term administration (during an acute episode or exacerbation) in RA (selected cases may require low dose maintenance therapy).

Objectives: This is an interim analysis from a multicenter, 2-part study evaluating the efficacy and appropriate duration of $\mathrm{RCl}$ therapy in patients with persistently active RA despite receiving 1-2 DMARDs and corticosteroids.

Methods: The study includes a 12-week open-label treatment period followed by a 12-week double-blind randomized maintenance phase for patients who achieve low disease activity (LDA) at Week 12. During the open-label period, all enrolled patients received $\mathrm{RCI} 80 \mathrm{U}$ subcutaneously (SC) twice per week. The primary endpoint was the proportion of patients that achieved LDA (ie, disease activity score with 28 joint count and erythrocyte sedimentation rate [DAS28-ESR] score $<3.2)$ at Week 12. The secondary endpoints were proportion of patients that maintained LDA from Week 12 to Week 24, time to disease activity flare, safety, and tolerability. Disease activity was also assessed by the proportion of patients that achieved improvements in American College of Rheumatology (ACR)20 ACR50, and ACR70 scores at Week 12

Results: As of December 18, 2017, 45 patients had completed the 12-week open-label treatment period of the study, and 12 patients had discontinued; $77.8 \%$ were female, with a mean age of 57 years. Patient baseline characteristics and the results of the primary and select secondary endpoints are presented in table 1, demonstrating that $\mathrm{RCl}$ allowed the majority of patients with RA to achieve LDA at Week 12. To date, 21 adverse events (AEs) and 1 serious AE (chest pain) have been reported. The most common AEs were headache (3), urinary tract infection (2), and fall (2).

Table 1. Patient Baseline and Endpoint Results at Week 12

\begin{tabular}{lll}
\hline Parameter & Baseline & $\begin{array}{l}\text { Week } \\
\mathbf{1 2}\end{array}$ \\
\hline DAS28-ESR Score, mean & & 3.6 \\
Tender Joint Count, mean & 6.5 & 3.5 \\
Swollen Joint Count, & 16.4 & 3.2 \\
mean & 12.5 & \\
LDA (DAS28-ESR <3.2) & & $55.6 \%$ \\
ACR20 & & $84.4 \%$ \\
ACR50 & & $57.8 \%$ \\
ACR70 & & $35.6 \%$ \\
\hline
\end{tabular}

Conclusions: Interim results from this ongoing clinical trial suggest that $\mathrm{RCI}$ can potentially be a safe and effective treatment alternative to improve multiple meas ures of disease activity in patients with persistently active RA despite therapy with DMARDs and corticosteroids.

Acknowledgements: Editorial support was provided by MedLogix Communications, LLC, Itasca, IL, under the direction of the authors and was funded by Mallinckrodt ARD, Inc., Bedminster, NJ.

Disclosure of Interest: R. Fleischmann: None declared, D. Furst: None declared, R. Brasington: None declared, E. Connolly-Strong Shareholder of: Mallinckrodt, ARD Inc, Employee of: Mallinckrodt, ARD Inc, J. Liu Shareholder of: Mallinckrodt, ARD Inc, Employee of: Mallinckrodt, ARD Inc, M. Barton Shareholder of: Mallinckrodt, ARD Inc, Employee of: Mallinckrodt, ARD Inc DOI: 10.1136/annrheumdis-2018-eular.5768

\section{SAT0249 2 REDUCTION OF MONOCYTE ACTIVATION BY BOWEL CLEANSE AND ONE WEEK FASTING SUGGESTS PERMANENT PATHOGENETIC TRIGGERING FROM THE GUT IN RHEUMATOID ARTHRITIS}

T. Häupl ${ }^{1}$, T. Sörensen ${ }^{1}$, M. Boyer ${ }^{1}$, J. Scheder-Bieschin ${ }^{2}$, B. Smiljanovic ${ }^{1}$, N. Steckhan ${ }^{2}$, G.-R. Burmester ${ }^{1}$, B. Stuhlmüller ${ }^{1}$, C. Kessler ${ }^{2}$, M. Bonin $^{1}$, A. Grützkau ${ }^{3}$, A. Michalsen ${ }^{2} .{ }^{1}$ Rheumatology, ${ }^{2}$ Internal and Complementary Medicine, Charité, ${ }^{3}$ Deutsches Rheuma Forschungszentrum, Berlin, Germany

Background: Fasting can improve clinical disease activity in rheumatoid arthritis (RA) [1], but mechanism involved are not clear. Recently, we demonstrated that monocytes in RA express transcriptome patterns of increased myelopoiesis, premature egress from bone marrow and reduced circulation time as indicators of permanent activation of the innate immune response [2].

Objectives: We investigated the influence of bowel cleanse and fasting on monocyte subpopulations in the blood to determine the extent of microbiota and gut immunity related triggering of chronic inflammation in RA.

Methods: RA patients $(n=22)$ and controls ( $n=12$, metabolic syndrome), who presented for fasting according to the Buchinger procedure (bowel cleanse with colonoscopy fluid), were analyzed for DAS28, CrP, differential blood count and high resolution cytometric phenotyping at baseline, day 3 , day 7 (end of fasting) and day 10. ImmunoClust was applied for automated cell clustering [3].

Results: Disease activity was strikingly decreased after fasting in virtually all RA patients (DAS28 from 4.24 to $3.17, \mathrm{p}<0.00005$ ) with significant reduction already after 3 days $(p<0.01)$. This was accompanied by a significant decline of CrP and ESR. Differential blood count revealed a slight decrease in total leukocytes and significant reduction of lymphocytes and eosinophils in RA. However, these blood changes were also observed but on a lower level in the metabolic controls. The most dominant and RA specific effect was a significant reduction of total monocytes when compared to RA baseline or to controls at day 10. Deep profiling of the monocyte compartment revealed reduced non-classical $\left(\mathrm{CD} 14^{+} \mathrm{CD} 16^{+}\right)$and intermediate $\left(\mathrm{CD} 14^{++} \mathrm{CD} 16^{+}\right)$monocytes prior to fasting in RA compared to controls and confirmed previous results [2]. Bowel cleanse and fasting induced a significant increase of these two monocyte subpopulations by absolute counts and even more by percentage of total monocytes. This indicates reduced recruitment to inflamed tissue and prolonged circulation with more cells differentiating from classical to non-classical monocytes in the blood [4]. The decrease of lymphocytes in RA patients after fasting was characterized by a dominant reduction of 
naive T-, B-cells and CD16- NK-cells along with a relative increase in memory lymphocytes and $\mathrm{CD} 16^{+} \mathrm{NK}$-cells. These effects were also observed but less pronounced in controls.

Conclusions: Bowel cleanse and fasting in RA induces a reduction of inflammation related to monocyte activation and turnover immediately within few days. Changes in the monocyte compartment were specific for RA compared to controls and dominated the immunological changes, suggesting that innate triggering mechanisms from gut and its microbiota are etiologically relevant in RA.

\section{REFERENCES:}

[1] Kjeldsen-Kragh J, et al. Lancet 1991;338(8772):899.

[2] Smiljanovic B, et al. Ann Rheum Dis 2018;77(2):300

[3] Sörensen T, et al. Cytometry A 2015;87(7):603.

[4] Tak T, et al. Blood 2017;130(12):1474

Acknowledgements: Technical assitance: Silvia Pade, Barbara Walewska Funding: German Federal Ministry of Education and Research grant ArthoMark (01EC1009A), Corona-Stiftung grant BioFast (S199/10063/2016).

Disclosure of Interest: None declared

DOI: 10.1136/annrheumdis-2018-eular.7165

\section{SAT0250 THE DOSING OF INTRA-ARTICULAR TRIAMCINOLONE HEXACETONIDE FOR KNEE SYNOVITIS IN CHRONIC POLYARTHRITIS - A RANDOMIZED CONTROLLED STUDY}

T. Weitoft ${ }^{1}$, K. Öberg ${ }^{2}$. 'Section for Rheumatology, Center for Research and Development Uppsala University/Region of Gävleborg, Gävle, ${ }^{2}$ Rheumatology clinic, Falun Hospital, Falun, Sweden

Background: Intra-articular glucocorticoid (IAGC) injection treatment is an easy and effective way to treat signs and symptoms of arthritis and it has been used for decades. Serious adverse reactions are rare, but IAGC therapy has impact on endocrine balances. There is limited knowledge of the adequate dosing for different joints and dosing traditions vary all over world.

Objectives: To compare the relapse rate during 6 months after IAGC for knee synovitis, between two common doses (20 mg vs $40 \mathrm{mg}$ ) of triamcinolone hexacetonide (THA)

Methods: A total of 159 adult patients with rheumatoid arthritis (RA) or psoriatic arthritis (Psoa) and active knee synovitis were randomized to IAGC injection with either $20 \mathrm{mg}$ or $40 \mathrm{mg}$ THA blinded to the participants. The primary endpoint was relapse of arthritis. When symptoms from the treated joint recurred and signs of arthritis could be confirmed on a following clinical examination a relapse was recorded and days from injection to relapse was calculated. At the end of the observation period those without relapse had a phone call to verify persistence of good treatment response.

Results: In this material there was no significant difference in patient characteristics at baseline and the proportion of relapse after 6 months were equal in the treatment arms $(30 \%$ versus $32 \%, p=0.822)$. Additionally no significant differences were found in the subgroups with RA and Psoa patients.

Conclusions: To reduce the risk for endocrine side effects and as no difference in treatment outcome between the compared doses was found the lower $20 \mathrm{mg}$ THA dose should be preferred in IAGC treatment for knee synovitis in chronic polyarthritis.

Disclosure of Interest: None declared

DOI: 10.1136/annrheumdis-2018-eular.2483

\section{SAT0251 SELECTIVE GLUCOCORTICOID RECEPTOR MODULATOR SHOWS POTENT ANTI-INFLAMMATORY EFFECT WITH IMPROVED METABOLIC PROFILE IN A PHASE I STUDY SUPPORTED BY IN VITRO DATA}

T. Hegelund Myrbäck ${ }^{1}$, S. Prothon ${ }^{1}$, M. Dearman ${ }^{2}$, G. Edenro ${ }^{2}$, J. Leander ${ }^{1}$ M. Hashemi ${ }^{1}$, G. de Miquel ${ }^{3}$, R. Fuhr ${ }^{4}$, T. Körnicke ${ }^{4}$, Z. Tahib ${ }^{1}$, E.-M. Andersson ${ }^{5}$, P. Svanberg ${ }^{2}$, K. Edman ${ }^{6}$, R. Hendrickx ${ }^{2}$, C. Keen ${ }^{2}$, M. Kraan ${ }^{2}$, K. Johansson ${ }^{2}$, U. G. Eriksson", B. Carlsson"1, O. Vaarala ${ }^{2}$. ${ }^{1}$ Early Clinical Development, IMED Biotech Unit, ${ }^{2}$ Respiratory Inflammation \& Autoimmunity IMED Biotech Unit, ${ }^{3}$ Global Medicines Development, AstraZeneca, Gothenburg, Sweden, ${ }^{4}$ Early Phase Clinical Unit Berlin, PAREXEL International GmbH, Berlin, Germany, ${ }^{5}$ Cardiovascular \& Metabolic Disease IMED Biotech Unit, ${ }^{6}$ Discovery Science, AstraZeneca, Gothenburg, Sweden

Background: AZD9567 is a novel oral selective glucocorticoid receptor modulator (SGRM) developed to have an improved safety profile versus prednisolone while maintaining efficacy.
Objectives: To show clinical evidence of safety differentiation for AZD9567 compared to prednisolone with respect to glucose homeostasis and to investigate the underlying effects on the glucose metabolism in human cell systems in vitro.

Methods: In a dose escalation study (NCT02760316), healthy volunteers were randomized to a 5-day once-daily treatment with AZD9567 (20, 40, 80, $125 \mathrm{mg})$ or prednisolone $(5,20,40 \mathrm{mg})$. We monitored the anti-inflammatory effect by TNF $\alpha$ release from ex vivo LPS stimulated whole blood and modelled the relationship with pharmacokinetics (PKPD). Plasma glucose was measured $\left(\mathrm{AUC}_{0-4 \mathrm{~h}}\right)$ during an oral glucose tolerance test (OGTT) before and after four days of treatment.

We also studied the effects of AZD9567 and prednisolone on mRNA expression of key gluconeogenesis enzymes (tyrosine aminotransferease (TAT), phosphoenolpyruvate carboxykinase (PEPCK) and glucose 6-phosphatase (G6Pase)) in primary human hepatocytes as well as on insulin secretion in human islets microtissues.

Results: The inhibition of TNF $\alpha$ release increased with the plasma concentrations of AZD9567. PKPD modeling of TNF $\alpha$ inhibition data showed that $40 \mathrm{mg}$ AZD9567 results in an anti-inflammatory activity similar to that predicted for $20 \mathrm{mg}$ prednisolone.

A significantly smaller increase of the glucose AUC was observed following treatment with 20 to $125 \mathrm{mg}$ AZD9567 compared to $20 \mathrm{mg}$ prednisolone $(\mathrm{p}<0.05)$. Mean $(95 \% \mathrm{Cl})$ changes from baseline for 20, 40, 80 and $125 \mathrm{mg}$ AZD9567 were $16 \%(6.5-26, n=7), 19 \%(9.3-30, n=7), 19 \%(9.8-30, n=7)$ and $34 \%(24-46, n=7)$, respectively. The corresponding values for 5,20 and $40 \mathrm{mg}$ prednisolone were $17 \%(10-24, n=13), 53 \%(43-62, n=13)$, and 68\% (58-79, $n=12)$, respectively. We found significant induction of TAT, PEPCK, and G6Pase mRNA in hepato cytes after prednisolone treatment. In contrast, AZD9567 did not change the expression of these enzymes and inhibited the effect of prednisolone when coadministered. Furthermore, AZD9567 showed less suppression of insulin secretion in human islets microtissues compared to prednisolone at concentrations with comparable inhibition of $\mathrm{TNF} \alpha$ release, resulting in a 12-fold better therapeutic ratio.

Conclusions: In healthy individuals, AZD9567 showed significantly reduced effect on glucose homeostasis versus prednisolone at doses with similar antiinflammatory activity. Thus, AZD9567 shows potential as an anti-inflammatory treatment with an improved metabolic safety profile compared to prednisolone.

Disclosure of Interest: T. Hegelund Myrbäck Employee of: AstraZeneca, S Prothon Employee of: AstraZeneca, M. Dearman Employee of: AstraZeneca, G. Edenro Employee of: AstraZeneca (former emplyee), J. Leander Employee of: AstraZeneca, M. Hashemi Employee of: AstraZeneca, G. de Miquel Employee of: AstraZeneca (former emplyee), R. Fuhr Employee of: Parexel International $\mathrm{GmbH}$, T. Körnicke Employee of: Parexel International GmbH, Z. Tahib Employee of: AstraZeneca, E.-M. Andersson Employee of: AstraZeneca, P. Svanberg Employee of: AstraZeneca, K. Edman Employee of: AstraZeneca, R. Hendrickx Employee of: AstraZeneca, C. Keen Employee of: AstraZeneca, M. Kraan Employee of: AstraZeneca (former emplyee), K. Johansson Employee of: AstraZeneca (former emplyee), U. Eriksson Employee of: AstraZeneca, B. Carlsson Employee of: AstraZeneca, O. Vaarala Employee of: AstraZeneca DOI: 10.1136/annrheumdis-2018-eular.5451

\section{SAT0252 CLINICAL AND FUNCTIONAL RESPONSE TO TOFACITINIB AND ADALIMUMAB IN PATIENTS WITH RHEUMATOID ARTHRITIS: PROBABILITY PLOT ANALYSIS OF RESULTS FROM THE ORAL STRATEGY TRIAL}

T. Takeuchi ${ }^{1}$, J. S. Smolen ${ }^{2}$, R. Fleischmann ${ }^{3}$, N. likuni ${ }^{4}$, H. Fan ${ }^{5}$, K. Soma ${ }^{6}$, E. Akylbekova ${ }^{7}$, T. Hirose ${ }^{8}$. ${ }^{1}$ Keio University, Tokyo, Japan, ${ }^{2}$ Medical University of Vienna and Heitzing Hospital, Vienna, Austria, ${ }^{3}$ Metroplex Clinical Research Center and University of Texas Southwestern Medical Center, Dallas, TX, ${ }^{4}$ Pfizer Inc, New York, NY, ${ }^{5}$ Pfizer Inc, Collegeville, PA, ${ }^{6}$ Pfizer Inc, Groton, CT, ${ }^{7} I Q V I A$, Durham, NC, United States, ${ }^{8}$ Pfizer Japan Inc, Tokyo, Japan

Background: Tofacitinib is an oral Janus kinase inhibitor for the treatment of rheumatoid arthritis (RA). ORAL Strategy (NCT02187055), a 12-month, global, Phase $3 b / 4$ study, demonstrated that in patients with RA and an inadequate response to methotrexate (MTX), tofacitinib + MTX was non-inferior to adalimumab + MTX, while tofacitinib monotherapy was not non-inferior to either combination based on American College of Rheumatology (ACR)50 response rates at Month 6.

Objectives: To assess clinical and functional efficacy across treatments in the ORAL Strategy trial using cumulative probability plots.

Methods: Efficacy was evaluated between patients who received tofacitinib 5 $\mathrm{mg}$ twice daily (BID) as monotherapy $(\mathrm{N}=384)$, tofacitinib $5 \mathrm{mg}$ BID + MTX $(\mathrm{N}=376)$ and adalimumab $40 \mathrm{mg}$ subcutaneously once every 2 weeks + MTX $(\mathrm{N}=386)$ based on ACR responses and changes from baseline in Health Assess ment Questionnaire-Disability Index ( $\triangle \mathrm{HAQ}-\mathrm{DI})$ score at Month 12. Cumulative probability plots for ACR-n (where ACR is the \% improvement from baseline in ACR components, and $n$ represents the mimimum $\%$ achieved by each patient) 